\title{
Students' Abstraction Process Based on Compression into Thinkable Concept from Blending Embodiment and Symbolism under Context Lesson Study and Open Approach
}

\author{
Nisara Suthisung ${ }^{1}$, Maitree Inprasitha ${ }^{2}$ \\ ${ }^{1}$ Doctoral Program in Mathematics Education, Faculty of Education, Khon Kean University, \\ Khon Kean, Thailand \\ ${ }^{2}$ Center for Research in Mathematics Education, Faculty of Education, Khon Kean University, \\ Khon Kean, Thailand \\ Email:muinisara@hotmail.com
}

Received June 26 $6^{\text {th }}$, 2012; revised July 29 ${ }^{\text {th }}$, 2012; accepted August 26 $6^{\text {th }}, 2012$

\begin{abstract}
The objective of mathematics learning and teaching was to develop students' concept in content so that the persons as teachers, educators, and researchers would try to search for instruments, and know for comprehending the students' existing concepts. The study abstraction process based on compression into thinkable concept was to be a major guideline in considering and findings answer in order to understand the students' concept (Gray \& Tall, 2007). In Thai classroom using Lesson Study and Open Approach produced the students' mathematical thinking by using open-ended problems with designed material for supporting interaction of students and their problem solving arithmetic (Inprasitha, 1997). According to view of Tall (2007a) suggested a parallel construction of compression in the symbolism and embodiment to thinkable concept. This paper aim to analyze the students' abstraction process based on compression into thinkable concept from blending embodiment and symbolism. The four first grader as targeted group at Kookham Pittayasan School, a project school with supported by CRME, Faculty of Education, Khon Kaen University, Thailand. For research design used ethnographic study and teaching experiment. The collected data were used video analysis, interviewing, and students' task analysis. The research revealed that, the students' thinking shift steadily from performing sequence of parallel compression from actions being linked together in increasingly sophisticated ways to thinkable concept in embodiment and symbolism. This research revealed that Lesson Study incorporated Open Approach as teaching approach provided to students' abstraction process from considering that they manipulated with designed materials for supporting and checking their various symbolic thinking before into same effect on arithmetic operation.
\end{abstract}

Keywords: Lesson Study; Open Approach; Abstraction Process; Embodiment and Symbolism; Compression to Thinkable Concept

\section{Introduction}

The objective of Mathematics Learning and Teaching was to develop students' concept in content so that the person as teachers, educators and researchers would try to search for instruments and know for comprehending the students' existing concepts (Gray \& Tall, 2007). Teachers need to know, to support and develop students' thinkable concept from learning activities, to bridge real world and mathematical world using problem solving as well as designing materials and tools. Students manipulated with designed materials for supporting, calculating, checking their results and they built thinkable concept.

To consider thinkable concept, Skemp (1987) suggested process of abstraction as a tool to build thinkable concept. Skemp (1971) considered the fundamental human thinking activities to be perception, action and reflection. Tall (2004) considered that the progress of students' mathematical thinking based on two fundamental human activities: perception and action which is develop through compression to thinkable concept in accordance with Gray and Tall (2007).

Gray and Tall (2007) suggested that the abstraction process through compression to thinkable concept is the key to develop increasingly powerful thinking. Tall (2007a) noted that thinkable concept must be integrated in the curriculum. However, there was no empirical evidence. So the researchers and educators should study and make it clear for teachers, students and parents (Tall, 2007a).

The abstraction process on an operation problem solving arithmetic using procedures in thinking are compressed to thinkable concept, according to Gray and Tall (2007) suggested that for long term learning concept formation, thinkable concept must be integrated in the curriculum. Gray and Tall (1994) suggested the abstraction process of compression operation arithmetic using procedures in problem solving to same effect. Tall (2004) explained that the changing process from procedures to thinkable concept cannot be seen easily. So, this is a point of view important of Tall and Isoda (2007) said that for classroom developed through Lesson Study provided to compression through four steps based on Tall (2006b) to be five steps of compression to thinkable concept.

In Thailand, under context of Lesson Study and Open Approach, Inprasitha et al. (2007) explained that Lesson Study focused on changing to develop the learners' progress in real class with 3 steps: team collaboration, observation and reflec- 
tion. And Open Approach as a teaching approach is an innovation for learning and developing students' abilities. According to Inprasitha (2010), Open Approach is a teaching approach to support and help the students to learn to the best of their abilities including 4 steps as following: posing open-ended problem, students self learning, whole class discussion and comparison, and summary through connection. The students' perceived real world embedded in the open-ended problems through attentively interacting with designed materials for supporting various students' thinking way.

To survey teachers' opinions in four schools, participating in the project under Center for Research in Mathematics Education, Faculty of Education, Khon Kaen University for four years using Open approach had found that the teachers concerned and required to provide the students' concept formation.

Inprasitha (1997) and Shimada and Becker (1997) suggested problem situation in mathematical activities that bridge real world and mathematical world. Nohda (1998) viewed that Open Approach is a teaching activity used for integrating mathematical activity and students' thinking, and explained that the mathematical activity is considered to be an activity in the abstraction process from real world to mathematical world. This study used Lesson Study and Open Approach to produce the students' mathematical thinking by focusing on open-ended problems with designed material for supporting interaction of students and their problem solving arithmetic. According to Poynter (2004), and Tall (2007a) noted that to a parallel construction of compression in the symbolism and embodiment to thinkable concept. In addition to this, Tall (2007b) suggested that Lesson Study provided area of the students' compression to thinkable concept.

From this point of view, the researcher interested to study the students' abstraction process through compression to thinkable concept from blending embodiment and symbolism in context using Lesson Study and Open Approach, which is a part in my research.

\section{Hypothesis}

Students' abstraction process is to be step up sequence of thinking to develop into concept.

\section{Research Question}

How is the students' abstraction process based on compression into thinkable concept from blending embodiment and symbolism?

\section{Research Objective}

To analyze the students' abstraction process based on compression into thinkable concept from blending embodiment and symbolism

\section{Methodology}

This research was conducted by Ethnographic Study and Teaching Experiment. Researcher treated Lesson Study as innovation instructional in classroom, Open Approach as sequence of teaching. Researcher as observation participates to describe school instructional culture which researcher embedded to study for 3 years.

And the teaching experiment as adopted in the study which incorporated Open Approach as teaching approach is targeted at and is hoped to throwing light on the understanding of students' abstraction process from connecting the action of a hand manipulative using designed materials to the effect of that action on the learning of arithmetic operation.

Used Teaching Experiment to see the students' process of abstraction based on action in compression to thinkable concept, observed several ways they use to solve problem and chose important concept to build thinkable concept. Researcher treated Open Approach as a sequence of teaching to provide various the natural thinking way in class to study target group using video, photographs, tape recording, field notes, interviewing teachers, teacher trainees and collaboratively observed in class to analyze the data as in framework. (It will be mention later.) Researcher embedded to study learning and teaching culture for 3 years, target group was one of four schools in the project under Center for Research in Mathematics Education, Faculty of Education, Khon Kaen University for 5 years. It was a small school with only one class in each grade. The first grade students were used Lesson Study and Open Approach in 3 steps collecting data as following:

Teaching plans were divided into two periods: before semester and after semester. Before semester, teachers, observers, internship mathematics student teachers, research team wrote teaching plan in units and periods, learning activities, objectives and open-ended problems using Japanese textbook. It was team collaboration of 4 schools. During semester, there were teaching plans on Tuesdays for this school, using students' concept in class students' background knowledge, experiences as well as expecting students' ideas in doing mathematical activities, open-ended problems. There was instruction for students to reveal thinking concept during doing mathematical activity and to create teaching plans and materials together. In class teaching focused on 4 steps of Open Approach: posing open-ended problem situations, student's self learning, whole class discussion and comparison, and summary through connection. The data was collected by tape recording and analyzed with the other steps.

At the teaching step, teachers taught in class after team planning, focused on the important of thinking time, and the students presented their work in front of class. Teachers walked around to see the students' concept, to arouse them showing their way of thinking, and help them in class presentation by using authentic teaching materials. Observer team (teachers, internship mathematics student teachers, school coordinators, and researcher) participated at this step in class by observing students' ideas and oral presentation in the classroom. Observer teachers, teachers, internship mathematics student teachers, research team, school administrators participated at this step. They observed students' tasks: oral and action to build thinkable concept according to four steps of Open Approach. Observer teachers, teachers, internship mathematics student teachers, research team, school administrators and experts participated at the reflecting step in each classroom from grade 1 to grade 9 . They observed students' concept and their tasks. The data was collected by tape recording, video and analyzed.

At the collaboration observation step, collected data from teaching experiment in class to see the procedures of 4 targeted students' abstraction process through compression to thinkable concept with conceptual analysis, using video recordings, field notes, pictures, interviewing witnesses in instruction background assembles (teachers, observer teachers and internship 
mathematics student teachers) and analyzing students' tasks with triangulation. The data was from class observing, interviewing and students' task. Exemplar analyzing students' concept using problem situation "get on the train” $(9+5-7=7)$ from team collaboration to build and analyze classroom teaching from planning lesson focused an open-ended problem situation as mention above. Observed students' oral and action presentation and analyzed their tasks. Analyzed empirical evidence in teaching scenes to understand how the students formulated the concept of "addition and subtraction". The purpose of analyzing teaching scenes was to study the students' abstraction process through compression to thinkable concept under classroom using Lesson Study and Open Approach. The data was analyzed under the framework that proposed by Tall and Isoda (2007). The analysis were divided into three parts: 1) analyzing students' way of thinking in solving problem; 2) Analyzing of compression into thinkable concept in students' abstraction process from calculation symbolic and interaction designed material; 3) Analyzing the students' abstraction process based on compression into thinkable concept from blending embodiment and symbolism under context using Lesson Study and Open Approach.

\section{Conceptual Framework}

Thinkable concept is the teaching and learning goals. In achieving that, teachers should provide appropriate learning experiences for learners. Open Approach as a teaching approach which cooperates with Lesson Study is the effective way to develop mathematical activity using open-ended problems for promoting and developing students' concept. To consider process of abstraction focused on compression to thinkable concept of interacting with learning materials and symbolic calculation in students' real world under the views as Figure 1.

\section{Context of Study: Lesson Study and Open Approach}

\section{Lesson Study}

At present Lesson Study has been used widely. Many educators state compatible the important of Lesson Study. Lewis (2002) viewed that Lesson Study is teachers' collaboration for learning aim and developing students' progress, designing lesson plans to support teaching and changing classroom. Tall (2007b) suggested that Lesson Study is pattern for construction, analyzing classroom and developing students' abilities thinking which teachers and researchers working together. And mathematics Lesson Study is individual lesson design to long-term teaching approach. Tall (2008) explained Lesson Study is a complete preparation lesson which learners construct mathematics concept and develop their own thinking concept.

For Thailand, Lesson Study is implied from Japan to improve and develop classroom teaching in real class, focusing on students' progress in class and exchanging knowledge and problems with other teachers. And teachers in group realize the teaching aim and adapt lesson to context in 3 steps: 1) Using Open Approach collaboratively for designing research lesson; 2) Observing; 3) reflection (Inprasitha et al., 2007).

This study used and treated Lesson study as pattern for constructing and analyzing classroom with based on learning and teaching with team (teachers, observers, internship mathematics student teachers, research team) collaboration to develop learning progress and the process of thinking as following.

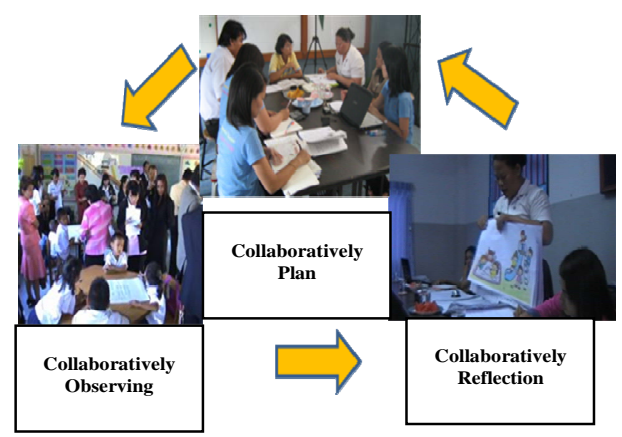

Figure 1.

Cycle of lesson study including 3 phases.

Collaboratively for designing lesson plan, using Open Approach form problem situation in students' real life, create designed materials to support students concept. Focused on lesson's goal, learn how to learn, timing for each period, designing 4 steps of teaching.

Collaboratively observe in class, bring the team teaching plan to use with Open Approach (It will be mentioned later). The team observed a teacher, the students' way of thinking, how they solved problems, their reaction to designed materials for using symbolic calculation to solve problem situation.

Collaboratively reflect, discussing problems and obstacles in using lesson plans as well as considering the position of using designed materials, students' way of solving problem, students' new ways of thinking, and the successful of using Lesson plans.

\section{Open Approach}

Nohda (1998, 2000) viewed that Open Approach is used for supporting various kinds of students activities and students mathematics thinking to solve problem. Open Approach is teaching approach which we can adapt to many students ways of thinking or we can say that students mathematical thinking and developing teaching approach should be integrated. Open Approach is expected to be a tool for changing classroom, helping students to learn from their abilities. In Thailand, Lesson Study has been used with Open Approach as a teaching approach in four steps according to Inprasitha (2010). It is started from posing open-ended problem situation, student's self learning, whole class discussion and comparison, and summary through connection. Students learn and understand the contents by solving problems.

This research focused on Open Approach at the step of students' self-learning, to analyze the students' abstraction process. Students manipulated with designed materials, calculating, and using Lesson Study to build thinkable concept.

1) Posing open-ended problem: A teacher posed problem to encourage students to solve problem (Figure 2(a)).

2) Students' self learning: They made goal-directed thinking, attempted to solve problem with different methods (Figure 2(b)).

3) Whole classroom discussion and comparison: The students presented their ideas in front of the class. They realized and checked way of thinking in order to systematically explain their ideas (Figure 2(c)).

4) Summary through connection: At this step, the teacher summarized the students' concept to help them understand the content (Figure 2(d)).

Inprasitha (2010) suggested in classroom using Lesson Study 
is integrated Open Approach provided and supported various students' way mathematical thinking, that is in first phase (collaboratively plan)—-team lesson planned lesson and teaching sequence based on 4 steps Open Approach: posing open-ended problem, students' self learning, whole class discussion and comparison, and summary through connection. In second phase (collaboratively observed) - team lesson observed students' mathematical thinking following 4 steps of Open Approach. In finally phase (collaboratively reflect)-team lesson reflect students' mathematical thinking happened following team lesson's expecting and coming out to develop lesson later (Figure 3).

\section{Conceptual Framework for Analysis the Students' Abstraction Process Based on Compression into Thinkable Concept from Blending Embodiment and Symbolism}

\section{Abstraction Process}

Skemp (1971, 1987) considered the fundamental human thinking activities to be perception, action and reflection. Tall (2004) described the process of abstraction through perception and action and Gray and Tall (2007) viewed that the abstraction process to develop through compression to thinkable concepts too. They described that the abstraction process through compression to thinkable concept is the key to develop increasingly powerful thinking. Lesson Study and Open Approach is an important teaching approach that arouses the students to think and act, to solve problem from blending embodiment with symbolism, so it is used in this research.
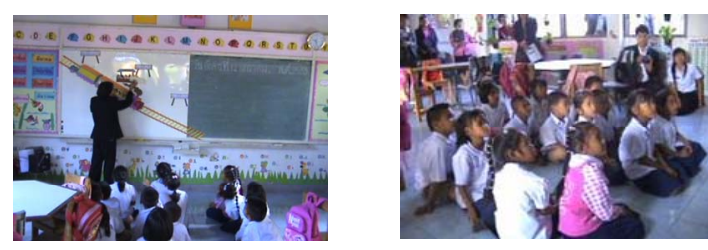

(a)
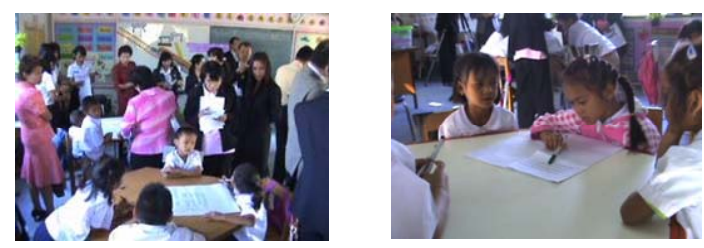

(b)
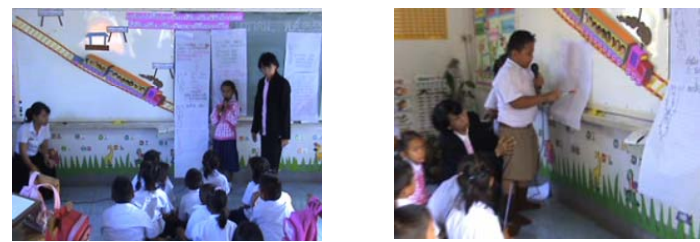

(c)
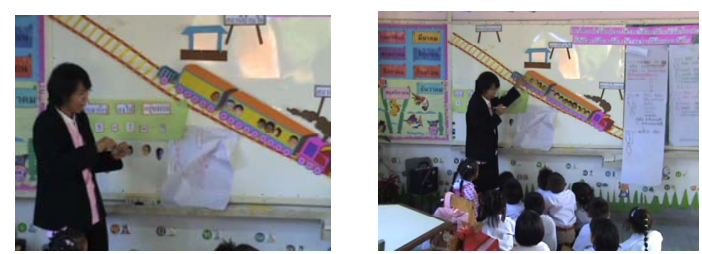

(d)

Figure 2.

4 steps of open approach.
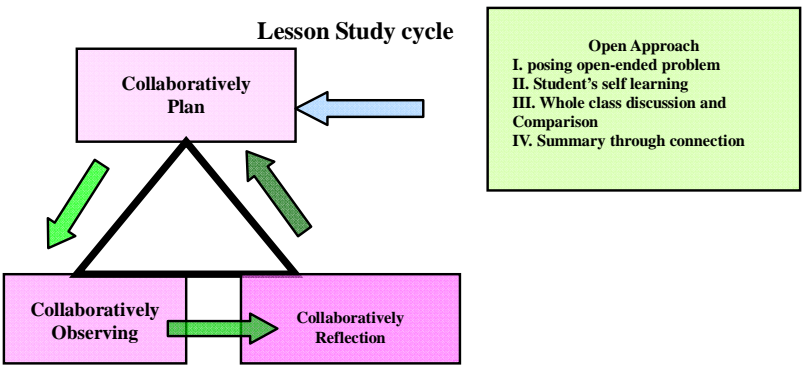

Figure 3.

Lesson study cycle and implementing open approach by focus on openended problem situation.

\section{Blending Embodiment and Symbolism}

Tall (2008) said that Lesson Study is lesson preparation for developing students' mathematical thinking from embodiment to symbolism or vice versa. Tall (2006a) found the parallel construction of embodiment and symbolism, the first could be seen but the second based on human thinking from symbolic calculation through thinkable concept, and Tall (2007b) developed research framework through conceptual embodiment and proceptual symbolism. In addition to this, Tall (2007a) noted that to a parallel construction of compression in the symbolism and embodiment to thinkable concept (Figure 4).

This study presented the process of abstraction focused on action; it can be seen through compression to thinkable concept in blending embodiment and symbolism from empirical evidence. Using Lesson Study and Open Approach produced the students' mathematical thinking by focusing on open-ended problems with designed material for supporting interaction of students and their problem solving arithmetic.

\section{Compression to Thinkable Concept}

Tall and Isoda (2007) said that for classroom developed through Lesson Study does not limit students to think, it helps the students to think and act differently in solving problem to same effect through four steps of compression to thinkable concept as following:

1) a procedure; 2) multi-procedure (and used the most efficient); 3) an overall process: to recognized the different ways that related in each steps to same effect; 4) a thinkable concept or procept according to Gray and Tall (1994): it is dually characteristics of process in calculation to same effect through compression to thinkable (Figure 5).

The above concept based on Tall (2006b), developed the continuously 5 steps through compression: 1) pre procedure; 2) a procedure; 3) multi-procedure; 4) a process; and 5) thinkable concept.

In addition Poynter (2004) explained the abstraction process combined manipulation on physical objects and symbols to support students' mathematical thinking: 1) action; 2) multiaction; 3) same effect; and 4) effect as prototype. Tall (2007a) noted that to a parallel construction of compression in the symbolism and embodiment to thinkable concept. This study presented the students' abstraction process in specific problem situations to thinkable concept in blending embodiment (learning materials) with (symbolism) written symbol (Figure 6).

\section{Analysis and Results}

Exemplar in analyzing grade 1 activity "get on the train”. A 


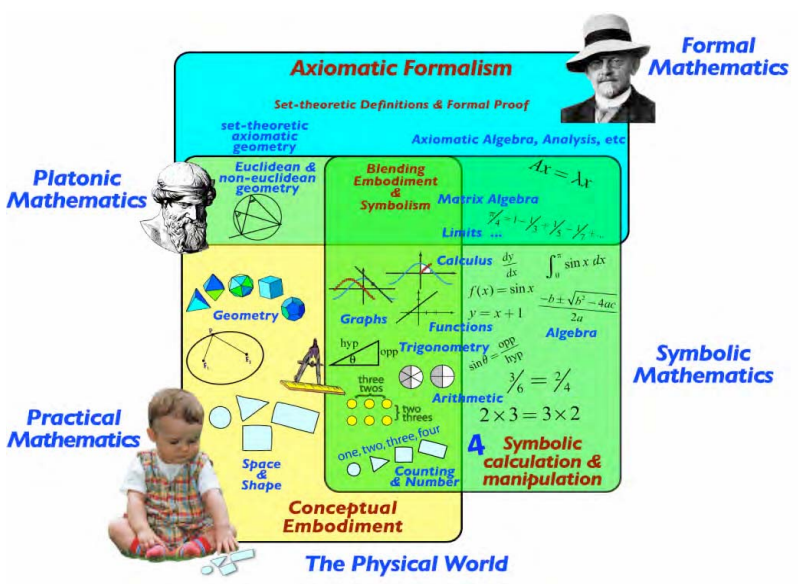

Figure 4.

Blending embodiment and symbolism in mathematical development (Tall, 2007b).

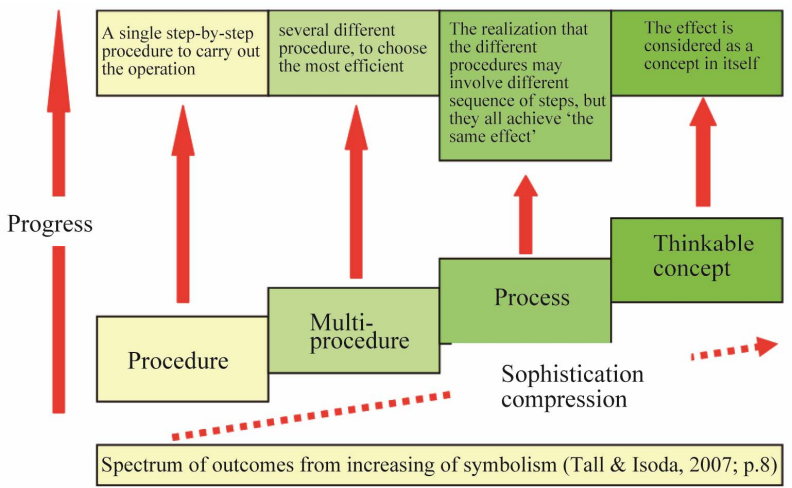

Figure 5.

Compression to thinkable concept in symbolism (Tall, 2006b).

\begin{tabular}{l} 
CONCEPUTAL \\
KNOWLEDGE \\
\hline
\end{tabular}

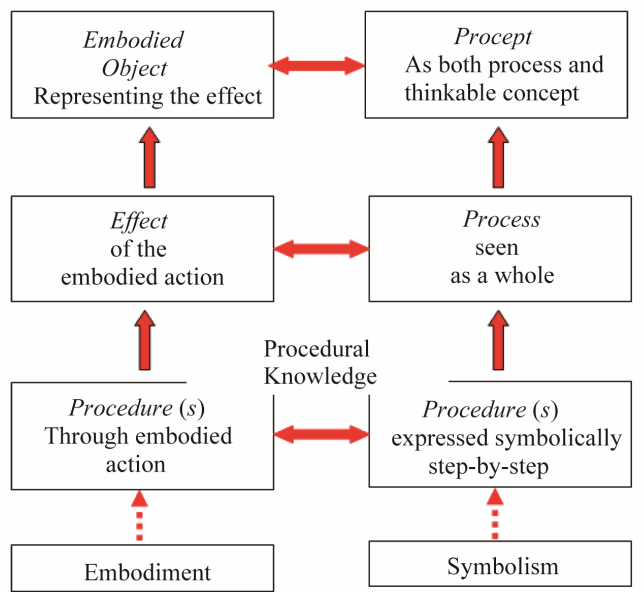

Figure 6.

A pararell compression to thinkable concept in embodiment and symbolism (Tall, 2006b).

teacher presented problem situation and stuck the designed material instruction on the blackboard for students. They read
"There are 9 students at Khon Kaen station, 5 students get on the train at Ban Pai and 7 students get off at Muang Phol station, so how many students are there on the train?” Learning materials were some paper, a picture of running train and a picture of each student on the train. Students background knowledge was construct 10 from decomposing and composing, using diagram as thinking tool. This situation focused on writing symbols addition and subtraction using diagram and base 10 based on analyzing data under the theory of Tall and Isoda (2007).

Problem situation "get on the train" was closed to students' daily lives and used a picture as teaching tool to arouse students to solve problem on open-ended problem situation. To find answer and use Open Approach as teaching tool for supporting and promoting students' abstraction process to thinkable concept.
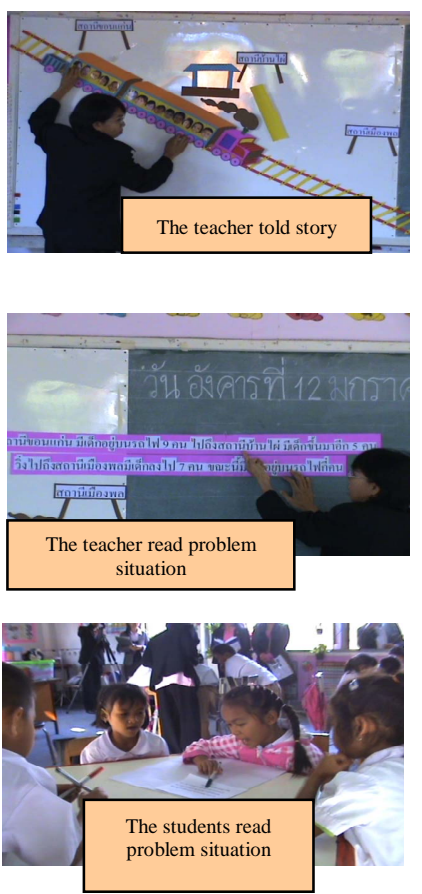

Students used base 10 and diagram as thinking tool to same result. Students decompose the first and second number and compose numbers to build 10 and decompose 10 with the third number. Students understood + for addition, - for subtraction $(9$ $+5-7=7$ ). They checked the result by picking the learning materials (As in Figure 7).

\section{Analyzing Students' Way of Thinking}

The focus switches to the number of children on the train, which can be found by the action of counting. Looking at different ways of performing the operation, as $9+5$ then take away 7 or $9+1$ making ten, plus 4 and taking away 7 , and so on. This is the operational world of mathematics in which different operations can have the same effect. It is the effect, the total number, which matters.

This is performed even more efficiently by simply focusing on numbers and their operations and, in particular, the flexibility of those operations. It means not just knowing lots of different ways of doing something, it means simplifying the prob- 


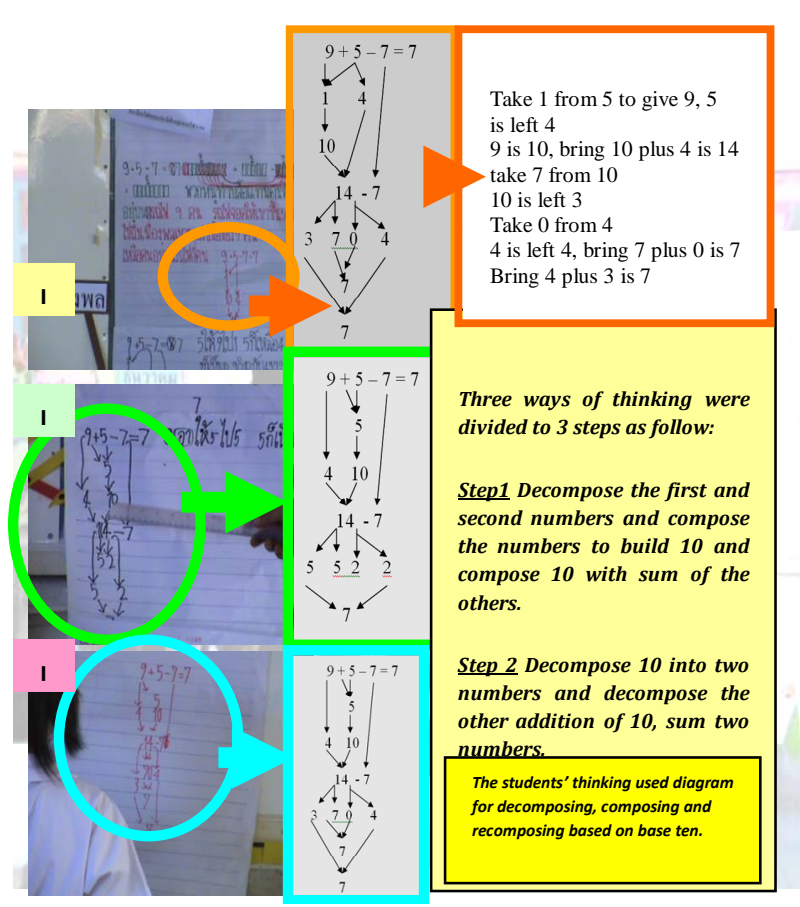

Figure 7.

The students' thinking using diagram for decomposing, composing and recomposing based on base ten.

lem by choosing an efficient and meaningful way of getting the answer, to make the arithmetic simpler.

Students used base 10 and diagram as thinking tools for the same result. Students' ways of thinking were decompose the first and second number and compose numbers to build 10 and subtract from the third number to find answer. Students understood the symbol + for addition, - for subtraction from symbolic sentence $(9+5-7=7)$. At last they checked the answer by picking designed materials. The answer was 7 as from symbolic sentence, and the students' way of thinking was divided into three steps to the same effect: building 10 with other numbers decompose 10 to subtract from the other number and compose number from step two.

Analyzing of compression into thinkable concept in students' abstraction process from calculation symbolic and interaction designed material:

Considering from procedure in problem to thinkable concept, students had several thinking methods in solving problem based on Tall and Isoda (2007), especially in final step the students revised and checked, they recognized concept formation and this concept was built to utilize later for extending mathematical structure (Suthisung \& Sangaroon, 2011a, 2011b, 2011c), which will be analyzed in area the students' abstraction process.

Gray and Tall (2007) suggested that for classroom developed through Lesson Study in four steps of compression to thinkable concept: I. A procedure, II. Multi-procedure, III. An overall process, IV. A thinkable concept and Suthisung and Sangaroon (2011a, 2011b, 2011c) studied according to the concept mentioned earlier, had found the fifth step revise thinkable concept.

From the above concept, students used 3 methods from compression to thinkable concept to same effect and they knew that $9+5-7=7$ were several ways of thinking. According to Howat (2005) suggested students used base 10 as thinkable concept. They used 10 and wrote symbolic sentences to same effect: $9+5-7=7,9+1+4-7,7+3+4-7,4+10-7,4+$ $\underline{5+5}-7,2+2+\underline{5+5-7}, 4+\underline{7+3}-7$. The students' way of thinking was divided into three steps to the same effect: building 10 with other numbers decompose 10 to subtract from the other number and compose number from step two.

And learning designed materials were related to symbolic calculation, used to check the result from problem situation: there were 9 students on the train and then 5 students got on, there were 14 students on the train and after that 7 students got off, so there were 7 students on the train. In addition, the students' abstraction process in "action”, the students used learning tools to support their thinking. According to Poynter (2004) explained the abstraction process combined manipulation on physical objects and compression to thinkable concept in 4 steps: I. Action; II. Multi-action; III. Same effect; IV. Effect is prototype, and Suthisung and Sangaroon (2011a, 2011b, 2011c) studied and found V. Effect is used (Summarized in Table 1).

The study revealed that the students thought and checked their answers by using designed materials step by step in solving problem as in Table 1 and in accordance with Tall (2007a)

Table 1.

Action of abstraction process focusing on compression to thinkable concept from blending embodiment and symbolism.

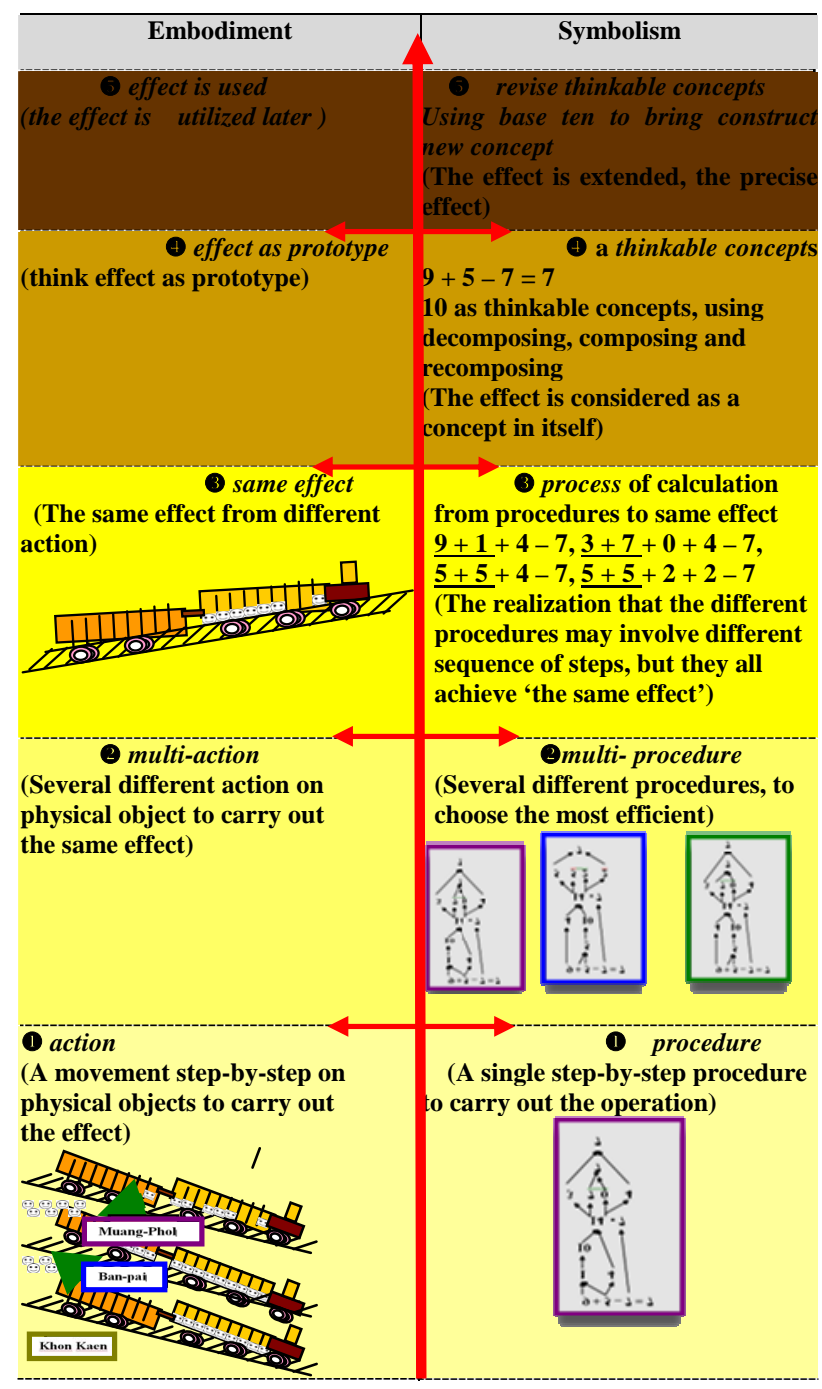




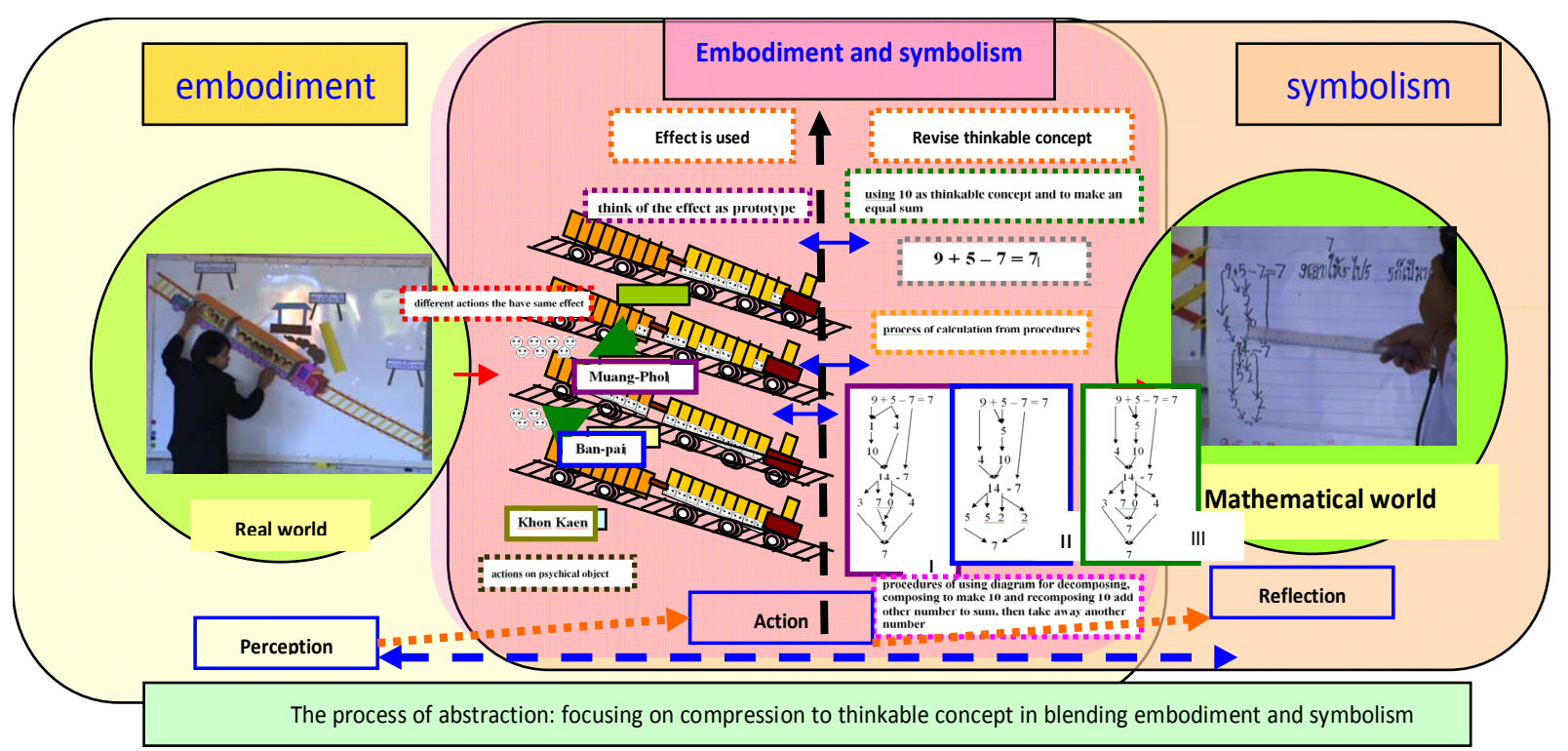

Figure 8.

The process of abstraction: focusing on compression to thinkable concept in blending embodiment and symbolism.

noted that to a parallel construction of compression in the symbolism and embodiment to thinkable concept.

Students used learning designed materials to support and promote their action in problem solving. They used multi-procedures to solve problems to same effect. The integration between learning designed materials and symbolic thinking supports the students to think quickly and efficiently.

Besides, the students used base 10 in addition and subtracttion to find the answer. They used 10 for decomposing, composing and recomposing according to Gray and Tall (1994) to build thinkable concept. Tall and Isoda (2007) said that the different procedures to the key concept and the students recognized and used various methods to build thinkable concept.

The students' abstraction process in action through compression to thinkable concept happened step by step in interacting with designed materials and symbolism.

Poynter (2004) and Tall (2007a) said that the compression to thinkable concept combined manipulation on physical objects and symbols to support students' mathematical thinking. The symbolic thinking and using learning designed materials to the same effect based on Tall (2007b) suggested a parallel construction of compression to thinkable concept from blending embodiment and symbolism.

Analyzing the students' abstraction process based on compression into thinkable concept from blending embodiment and symbolism under context using Lesson Study and Open Approach:

The students manipulated with designed materials for supporting and checking their various symbolic thinking before into same effect on arithmetic operation. In the students' abstraction process based on action, the students' thinking shift steadily from performing sequence of compression from actions being linked together in increasingly sophisticated ways to thinkable concept in embodiment and symbolism. According to Poynter (2004) purposed that compression in embodiment including action, multi-action, same effect, effect as prototype and expanded to effect is used. According to Tall and Isoda (2007) purposed that compression in symbolism including pro- cedure, multi-procedure, process, a thinkable concept (procept) and expanded to revise thinkable concept as in solving mathematics problem.

Moreover, the classroom using teaching with Open Approach which is driven by Lesson Study, the implementation of abstraction process started in step of Posing open ended problem-the students had perception through seeing and interacting with designed materials as well as problem situations. Consequently, the students were interested in and persistent in meaningful problem solving leading to duration in step of Students' self-learning - the students tried to use various procedures in problem solving from the designed material, mathematical symbolic thinking, language usage in explaining as well as writing mathematical symbols systematically. Consequently, the students used considered the way of thinking and refined the importance ideas by critical thinking and careful reflective thinking in order to develop major approaches from different problem solving procedures through 5 steps of compression to thinkable concept. In step of Whole class discussion and comparison-the students investigated their own thinking way and share ideas from their friend and teacher. In step of Summary through connection - the students had opportunity in reviewing as well as viewing the value of the occurred tools of thinking from their problem solving procedures (Figure 8).

\section{Conclusion and Discussion}

The research revealed that, Lesson Study incorporated Open Approach as teaching approach provided to students' abstracttion process in step students' self learning from considering that they manipulated with designed materials for supporting and checking their various symbolic thinking before into same effect on arithmetic operation. The students' thinking shift steadily from performing sequence of compression from actions being linked together in increasingly sophisticated ways to thinkable concept in embodiment from action to effect onto effect is used and symbolism from process to concept onto revise thinkable concept respectively. 
Especially, the parallel compression to thinkable concepts in embodiment and symbolism that is compression in embodiment including action, multi-action, same effect, effect as prototype and expanded to effect is used. Compression in symbolism including procedure, multi-procedure, process, a thinkable concept (procept) and expanded to revise thinkable concepts as in solving mathematics problem. It is shifting steadily from performing sequence of compression in students' thinking from actions being linked together increasingly sophisticated ways: accumulation students' way thinking in 1 - 3 steps to refine important ideas in step 4 and it is realized to extend useable mathematical structure in step 5 also. It happened clearly by compression of knowledge from step-by-step procedure, to the possible choice of several different procedures, to seen the overall effect as a general process that can be carried at in various ways, to compressing it as a thinkable concept.

The further study, my research will analyze the function of students' abstraction process as operation of compression to thinkable concept from blending embodiment and symbolism, which is micro scale in analyzing mechanism students' mathematical thinking.

\section{Acknowledgements}

This work was supported by the Higher Education Research Promotion and National Research University Project of Thailand, Office of the Higher Education Commission, through the Cluster of Research to Enhance the Quality of Basic Education and Center for Research in Mathematics Education, Faculty of Education, Khon Kaen University, Thailand.

\section{REFERENCES}

Howat, H. (2005). Participation in elementary mathematics: An analysis of engagement, attainment and intervention. Ph.D. Thesis, Coventry: University of Warwick.

Gakkoh, T. (2005). Study with your friends mathematics for elementary school 1st grade.

Gray, E., \& Tall, D. (1994). Duality, ambiguity and flexibility: A proceptual view of Simple arithmetic. Journal for Research in Mathematics Education, 25, 115-141. doi:10.2307/749505

Gray, E., \& Tall, D. (2007). Abstraction as a natural process of mental compression. Mathematics Education Research Journal, 19, 23-40. doi:10.1007/BF03217454

Inprasitha, M. (1997). Problem solving: A basis to reform math ematics instruction. Journal of the National Research Council of Thailand, 29, 221-259.

Inprasitha, M., Pattanajak, A., \& Thasarin, P. (2007). To prepare context for leading the teacher professional development of Japan to be called "Lesson Study" implemented in Thailand. Document Later National Academic Meeting Japanese Studies Network. Bangkok: Japanese Studies Network; Thailand: Thammasat University. 152163.

Inprasitha, M. (2010). One feature of adaptive lesson study in Thailand:
Designing a learning unit. Proceedings of the 45th Korean National Meeting of Mathematics Education, Gyeongju, 8-9 October 2010, 193-206.

Lewis, C. (2002). Lesson study: A handbook of teacher-led instructional change. Hiladelphla: Research for Better School, Inc.

Nohda, N. (1998). Mathematics teaching by "open-approach method" in Japanese classroom activities. Proceedings of ICMI-EARCOME 1, Cheongju, 17-21 August 1998, 185-192.

Nohda, N. (2000). Teaching by approach method in Japanese mathematics classroom. Proceeding of the 24th Conference of the International Group for the Psychology of Mathematics Education, Hiroshima, 23-27 July 2000, 11-39.

Poynter, A. (2004). Effect as a pivot between actions and symbols: The case of vector. Ph.D. Thesis, Coventry: University of Warwick.

Shimada, S., \& Becker, P. J. (1997). The open-ended approach: A new proposal for teaching mathematics. Reston: National Council of Teachers of Mathematics.

Skemp, R. R (1971). The psychology of learning mathematics. London: Penguin.

Skemp, R. R. (1987). The psychology of learning mathematics. Hove and London: Lawrence Erlbaum Associated, Inc., 9-21.

Suthisung, N., \& Sangaroon, K. (2011a). The steps up of compression to thinkable concept in action of the student's abstraction process. The 16th Annual Meeting in Mathematics, Khon Kaen, 10-11 March 2011, 413-432.

Sutisung, N., \& Sangaroon, K. (2011b). "How to" in the students' abstraction process through compression to thinkable concept. Proceedings of the 35th Conference of the International Group for the Psychology of Mathematics Education (Developing Mathematical Thinking), Ankara-Turkey, 10-15 July 2011, 1-398.

Sutisung, N., \& Sangaroon, K. (2011c). The students' process of abstraction based on action in compression to thinkable concept of blending embodiment and symbolism under context using lesson study and open approach. Proceedings of the 35th Conference of the International Group for the Psychology of Mathematics Education (Developing Mathematical thinking), Ankara-Turkey, 10-15 July 2011, 1-505.

Tall, D. (2004). The nature of mathematical growth. URL (last checked 2 January 2010). http://www.tallfamily.co.uk/davidmathematical-growth/

Tall. D. (2006a). A Theory of mathematical growth through embodiment, symbolism and proof. Annales de Didactique et de Sciences Cognitives, IREM de Strasbourg, 11, 195-215.

Tall, D. (2006b). Encouraging mathematical thinking that has both power and simplicity. Plenary Presented at the APEC-Tsukuba International Conference, Ichigaya, 3-7 December 2006, 1-15.

Tall, D. (2007a). Developing a theory of mathematical growth. ZDM Mathematics Education, 39, 145-154. doi:10.1007/s11858-006-0010-3

Tall, D. (2007b). Setting lesson study within a long-term framework of learning. Presented at APEC Conference on Lesson Study, Khon Kaen, 14 August 2007, 1-17.

Tall, D. (2008). Using Japanese lesson study in teaching mathematics. Scottish Mathematical Council Journal, 38, 45-50.

Tall, D., \& Isoda, M. (2007). Long-term development of mathematical thinking and lesson study. Prepared as a Chapter for a Forthcoming Bookon Lesson Study, 1-34. 